\title{
Hybrid occlusion of a paravalvular leak with an Amplatzer Septal Occluder after mechanical aortic and mitral valve replacement
}

\author{
Nora Lang, MD, ${ }^{\text {a }}$ Rainer Kozlik-Feldmann, MD, ${ }^{\mathrm{a}}$ Robert Dalla Pozza, MD, ${ }^{\mathrm{a}}$ Martin Hinterseer, MD, ${ }^{\mathrm{b}}$ \\ Ralf Sodian, MD, ${ }^{\mathrm{c}}$ Jan Abicht, MD,${ }^{\mathrm{d}}$ Christian Kowalski, MD, ${ }^{\mathrm{d}}$ Heinrich Netz, MD, ${ }^{\mathrm{a}}$ \\ Bruno Reichart, $\mathrm{MD},{ }^{\mathrm{c}}$ and Christoph Schmitz, $\mathrm{MD},{ }^{\mathrm{c}}$ Munich, Germany
}

Development of a paravalvular leak after prosthetic valve replacement is a rare but hard to treat complication. In many cases, it requires reoperation. Reoperation is associated with higher mortality and excess risk of recurrent paravalvular insufficiency. During the last couple of years, several hybrid procedures have been developed to decrease operative risk and trauma. ${ }^{1}$

\section{CLINICAL SUMMARY \\ Medical History}

We describe the case of a 66-year old man after replacement of the aortic and mitral valves (Medtronic Hall; Medtronic, Inc, Minneapolis, Minn) in 1989. In 2000, the ascending aorta was replaced, and a DDD pacer was implanted. In 2008, the patient had acute hemolysis, which necessitated periodic blood transfusions. Transthoracic echocardiography revealed a new paravalvular leak of the mitral valve (Figure 1). Because of multiple comorbidities (renal insufficiency, hypertension, previous hemicolectomy), we discussed with the patient the option of implanting an Amplatzer Septal Occluder in a hybrid fashion.

\section{Surgical Technique}

With the patient under general anesthesia, the chest was opened through a small $(8 \mathrm{~cm})$ left anterolateral thoracotomy to present the left ventricular apex. The pericardium was incised just above the apex, and two Teflon-armed purse-string sutures (Ethicon, Johnson \& Johnson, Norder Stedt, Germany) were placed on the left ventricular apex. A short $8 \mathrm{~F}$ sheath (Cordis, Johnson \& Johnson, Warren, NJ) was inserted through a stab wound incision into the left ventricle. A Terumo 0.025-inch guidewire (Termumo Medical Corporation, Somerset, NJ) was introduced under transesophageal echocardiographic and fluoroscopic guidance and pushed forward through the annular dehiscence into the left atrium.

From the Departments of Pediatric Cardiology, ${ }^{\mathrm{a}}$ Cardiology, ${ }^{\mathrm{b}}$ Cardiac Surgery, ${ }^{\mathrm{c}}$ and Anesthesiology, ${ }^{\mathrm{d}}$ University of Munich, Munich, Germany.

The Amplatzer Septal Occluder is manufactured by AGA Medical Corporation, Golden Valley, Minn.

Received for publication Sept 23, 2008; accepted for publication Oct 4, 2008; available ahead of print April 3, 2008.

Address for reprints: Christoph Schmitz, MD, Department of Cardiac Surgery, University of Munich, Marchioninistrasse 15, 81377 Munich, Germany (E-mail:

Christoph.Schmitz@med.uni-muenchen.de).

J Thorac Cardiovasc Surg 2010;139:221-2

$0022-5223 / \$ 36.00$

Copyright $₫ 2010$ by The American Association for Thoracic Surgery

doi:10.1016/j.jtcvs.2008.10.005

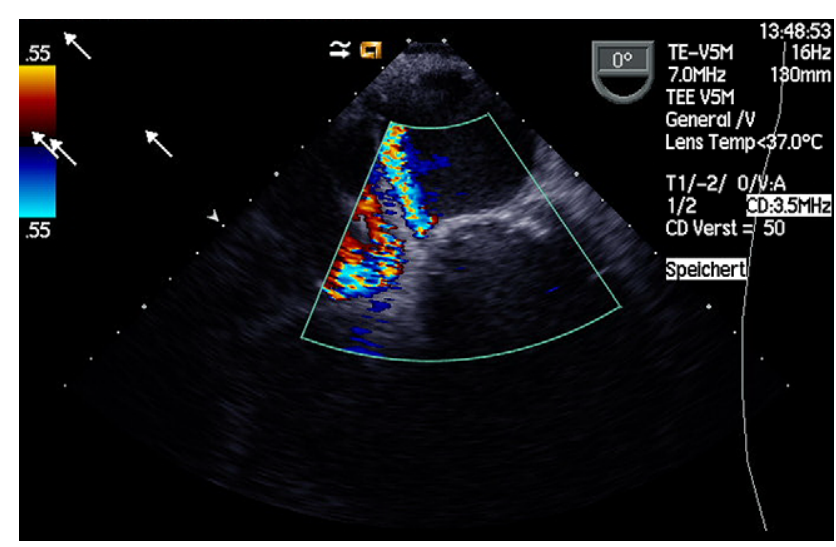

FIGURE 1. Preoperative echocardiography showing paravalvular leak of mechanical prosthesis in mitral position.

The sheath was advanced into the left atrium, and a 6-mm Membranous Amplatzer Septal Occluder (AGA Medical, Golden Valley, Minn) was implanted. After sheath removal, the purse-string sutures were tied, and the chest was closed in layers. Overall skin-to-skin operative time was 140 minutes.

\section{Postoperative Results}

The patient was weaned from the ventilator on postoperative day 1, was transferred from the intensive care unit on postoperative day 2, and was discharged home on postoperative day published 23. During the hospital stay, the pacemaker was replaced. Transthoracic echocardiography showed no residual leakage. Function of both valve prostheses was normal.

\section{DISCUSSION}

There have been several reports on closing paravalvular leaks with different umbrella-type devices. ${ }^{2,3}$ In all reports published to date, a percutaneous approach was used. In our case, such an approach was not possible because the patient had two mechanical valves. Passing a mechanical aortic prosthesis with a big, stiff sheath leads to significant aortic insufficiency. Furthermore, no valve company guarantees that the leaflets of the valves will stay in place when passing them with a stiff sheath. Another option, the antegrade approach to the mitral valve through a puncture in the atrial septum, is also extremely difficult, because the antegrade pathway to the mitral valve is very curvy.

In our case we discussed the options: a standard reoperation with median sternotomy, right lateral thoracotomy with 
cardiopulmonary bypass, or an off-pump hybrid procedure. As there was no need to exchange the well-functioning mitral prosthesis itself, we decided to go for the last option.

Approaching the paravalvular leak from the left ventricular apex turned out to be much easier than expected. The guidewire, which was approached first, fell more or less by itself into the dehiscence between the sewing ring and annulus. However, there was one delicate situation. During the pushing of the Amplatzer device out of the sheath, one leaflet of the mitral valve was blocked. It was hard to determine whether the umbrella itself or the sheath was responsible was responsible for this blockade. We pulled the introducer sheath back without detaching the umbrella. Fortunately, valve function returned to normal, proving that the sheath did indeed compromise function.

We believe that in this particular situation, a hybrid procedure, reduced the risk of the operative procedure significantly.

\section{References}

1. Schmitz C, Esmailzadeh B, Herberg U, Lang N, Sodian R, Kozlik-Feldmann R, et al. Hybrid procedures can reduce the risk of congenital cardiovascular surgery. Eur J Cardiothorac Surg. 2008;34:718-25.

2. Sivakumar K, Shahani J. Transcatheter closure of paravalvular mitral prosthetic leak with resultant hemolysis. Int J Cardiol. 2007;115:e39-40.

3. Webb JG, Pate GE, Munt BI. Percutaneous closure of an aortic prosthetic paravalvular leak with an Amplatzer duct occluder. Catheter Cardiovasc Interv. 2005;65: 69-72.

\title{
Complete lung parenchyma-sparing resection of the right main stem bronchus and bronchus intermedius
}

\author{
Justin H. Booth, BS, ${ }^{\mathrm{a}, \mathrm{c}}$ Roosevelt Bryant III, MD, ${ }^{\mathrm{b}, \mathrm{c}}$ Ara Vaporciyan, MD, ${ }^{\mathrm{b}}$ and David L. S. Morales, MD, ${ }^{\mathrm{b}, \mathrm{c}}$ \\ Houston, Tex
}

Pulmonary carcinoid tumors account for only $1 \%$ to $2 \%$ of all lung cancers, but they are the most common primary pulmonary neoplasm in the pediatric population. ${ }^{1}$ They are classified as typical or atypical on the basis of their clinical behavior and histologic findings. ${ }^{2}$ Although both types are considered malignant, the much more common typical carcinoids rarely metastasize to regional lymph nodes or distally and have an excellent prognosis with a 10-year survival of $82 \%$ to $100 \% .^{2}$ Complete surgical resection is the treatment of choice. Inasmuch as only negative margins are necessary and radical resection is rarely needed, every effort should be made to preserve as much lung parenchyma as possible.

We present a case of a typical carcinoid of the right airway treated with resection of the right main stem bronchus (RMB) and bronchus intermedius (RBI) with carinal reconstruction using the right lower lobe (RLL) and right middle lobe (RML) carina and creation of a pig bronchus (bronchus suis).

From the University of Texas Medical School at Houston, ${ }^{a}$ the Michael E. Debakey Department of Surgery, Baylor College of Medicine, ${ }^{\mathrm{b}}$ and the Division of Congenital Heart Surgery, Texas Children's Hospital, ${ }^{\mathrm{c}}$ Houston, Tex.

Received for publication April 1, 2008; revisions received April 23, 2008; accepted for publication May 13, 2008; available ahead of print March 9, 2009.

Address for reprints: Roosevelt Bryant III, MD, Texas Children's Hospital, 6621 Fannin St, Houston, TX 77030 (E-mail: rxbryan1@texaschildrenshospital.org).

J Thorac Cardiovasc Surg 2010;139:222-4

$0022-5223 / \$ 36.00$

Copyright (c) 2010 by The American Association for Thoracic Surgery

doi:10.1016/j.jtcvs.2008.05.070

\section{CLINICAL SUMMARY}

An 11-year-old boy with a history of upper respiratory infections and chronic fatigue was admitted with hemoptysis. Computed tomography of the chest and examination with a rigid bronchoscope demonstrated a right bronchial mass almost completely obliterating both the RMB and RBI. Biopsy demonstrated a grade I neuroendocrine carcinoid.

After intubation with a micro-long endotracheal tube placed in the left main stem bronchus, a right posterolateral thoracotomy incision was made. A vascular pedicled intercostal muscle was harvested.

Anteromedial retraction of the lung allowed visualization of the posterior aspect of the RMB. The tumor extended from the RMB orifice to halfway down the RBI along the airway's medial wall and did not seem to involve the right upper lobe (RUL) bronchus. Although the mass did abut the esophagus and pulmonary artery, there was no adherence. After resection of the level 10 and 11 lymph nodes, development of the minor fissure, and circumferential dissection of the RMB and RBI as well as all the hilar vessels, the RUL bronchus was transected. The RBI was transected at the level of the RML and RLL orifices and the RMB was transected at the carina. All tissues attached to the tumor and the level 7 lymph nodes were excised en bloc with the mass (Figure 1, A). Frozen sections of the bronchial and carinal margins were free of malignancy.

A complete hilar release was performed with the inferior vena cava released down to the diaphragm. The trachea 